\title{
Inmigrantes rumanas en el servicio doméstico y de cuidados de la Comunidad de Madrid: Estudio cualitativo ${ }^{1}$
}

\section{Romanian immigrants in the domestic service and of elderly care of the Community of Madrid: Qualitative study}

\begin{abstract}
Silvia Marcu*
"Tengo la satisfacción amarga del dinero. ¿Qué me toca cuidar un mayor? Pues, muy bien... ¿Qué me toca cuidar un niño? Mejor todavía... No importa qué puede ofrecerte la vida, porque nosotros estamos aquí para trabajar... y no llegamos con la posibilidad de escoger el trabajo, nosotros venimos pensando: espero encontrar trabajo en España, poder aguantar lo dura que es la vida de un inmigrante para mandar dinero a casa, ahorrar o pagar las deudas... con lo cual, no me molesta trabajar en el servicio doméstico, aún siendo informática."
\end{abstract}

(Mujer, 40 años.)

\section{INTRODUCCIÓN}

A finales del siglo xx y comienzos del siglo xxI hubo intensos cambios geopolíticos que transformaron el continente europeo. Rumania sufrió mutaciones importantes tras la caída del régimen dictatorial, y el comienzo de la transición política, económica afectó a toda la sociedad. España, por su parte,

\footnotetext{
* Instituto de Economía, Geografía y Demografía, CCHS, CSIC. (silvia.marcu@cchs.csic.es)

${ }^{1}$ El artículo utiliza las entrevistas en profundidad realizadas para el Proyecto de Investigación "Inmigración y cuidado de mayores en la Comunidad de Madrid" financiado por la Fundación BBVA (IEGD. CCHS 2006-2009). La autora formó parte del equipo investigador y realizó las entrevistas en profundidad al colectivo rumano, al que agradece su colaboración.
} 
se enfrentó a un intenso proceso de cambio social y demográfico, como punto de inflexión en su historia más reciente (Soriano, 2006).

Coincidiendo con la caída de los regímenes totalitarios en la Europa del Este, y la posterior transformación de España en país de inmigración (Bodega, Cebrián y Martín, 2006), en el mapa migratorio español se insertó Rumania, país que, paulatinamente, se convirtió en el más intenso emisor de flujos de inmigrantes. A lo largo de la década de los noventa, los flujos fueron moderados, pero a partir de 2002 se incrementaron de tal manera que, según el Avance del Padrón de Habitantes (junio de 2008)2 había 728.967 rumanos registrados en España (337.168 mujeres). Entre ellos, 189.001 (90.680 mujeres) vivían en la Comunidad de Madrid. Por primera vez, desde que el país ingresara en la Unión Europea (UE), los rumanos superaron en efectivos a los colectivos marroquí y latinoamericano.

El artículo analiza la situación laboral de las mujeres rumanas en el sector doméstico madrileño, teniendo en cuenta el benéfico encuentro entre la sociedad de acogida, envejecida y la necesidad de la mujer inmigrante de emplearse para mejorar su nivel de vida.

Para llevar a cabo el trabajo, se utilizó la metodología cualitativa ${ }^{3}$, con la realización de 20 entrevistas en profundidad ${ }^{4}$ a inmigrantes rumanas con edades comprendidas entre 26 y 61 años, que trabajan en domicilios de la Comunidad de Madrid 5 , en el servicio doméstico vinculado al cuidado de personas mayores ${ }^{6}$. (Anexo final). El cuestionario, de carácter abierto, se estructuró en tres partes: la primera abarca la situación de partida de la inmigrante encuestada, la segunda indaga en la situación laboral como empleada de hogar y como cuidadora de personas mayores en España (el acceso al cuidado, la relación laboral, la práctica de los cuidados, las tareas desempeñadas), mientras que la última parte procura observar el

2 Avance del Padrón de Habitantes, a 1 de Enero de 2008. Datos provisionales. 19 de Junio de 2008. www.ine.es.

${ }^{3}$ Para el análisis de los datos cualitativos, se utilizó el método de análisis del discurso con el soporte informático del ATLAS ti, 5.0.

${ }^{4}$ Las entrevistas se realizaron entre 15 de enero y 9 de febrero de 2008 en el idioma rumano. Fueron transcritas y traducidas al español, integralmente, por la autora de este artículo.

${ }^{5}$ Las entrevistas se realizaron en Madrid Capital, en Alcalá de Henares, en Coslada, en Móstoles, en Torrejón de Ardoz y Alcobéndas (siendo éstas, las localidades con mayor presencia de inmigrantes rumanas en la Comunidad de Madrid). El contacto se realizó a través de las Asociaciones de Inmigrantes Rumanas en la CAM.

${ }^{6}$ Se entrevistaron a 10 trabajadoras en régimen de interna, 6 en régimen de externa, 4 trabajadoras por horas. 
grado de satisfacción de las inmigrantes en relación con el trabajo desempeñado.

Si bien al plantear la investigación, se intentó detectar únicamente casos de inmigrantes que cuidan y atienden mayores en España, después de realizar el estudio exploratorio e indagar en la verdadera situación del mercado doméstico informal en la Comunidad de Madrid, se realizó el análisis de modo global. Las entrevistas en profundidad confirmaron el hecho de que el cuidado a mayores es un trabajo añadido al de empleada de hogar. Aunque se trata de dos actividades diferentes, en la práctica parecen constituir un ámbito de actividad único. En este sentido, se considera que la atención y cuidado de personas es una actividad productiva doblemente irregular:

1. Por un lado, porque se trata de una actividad cuya fórmula de contratación (si es que existe) se realiza en el marco del servicio doméstico.

2. Y por el otro, por el carácter irregular atribuido al propio servicio doméstico.

Hasta la actualidad, se han "escuchado" a los especialistas que defendían la legalización o la formación específica de los inmigrantes para trabajar en el sector, o las voces de los técnicos y especialistas en integración, pero la opinión de las inmigrantes todavía no se ha analizado. La aportación ofrece el punto de vista de las mujeres directamente implicadas en el sector informal del servicio doméstico de la CAM. La voz de las inmigrantes, sobre la realidad diaria vivida como empleadas de hogar, se convierte, pues, en la protagonista de este artículo.

INMIGRACIÓN, SERVICIO DOMÉSTICO Y DE CUIDADOS: UN CAMPO ABIERTO A LA INVESTIGACIÓN

El servicio doméstico es un ámbito de trabajo característico para la mujer. Aún hoy, el género lucha por incorporarse de manera estructural en la teoría migratoria. Los enfoques iniciales de teorías neoclásicas o estructuralistas se centraron en el nivel macro y las fuerzas atracción-expulsión con origen en las leyes de Ravenstein (1885), como las diferencias salariales y la demanda y oferta de trabajo. Estos enfoques, retomados bajo forma push pull (Everett, 1969) no incorporan ni las teorías sobre género ni una perspectiva feminista sobre la distribución de los recursos, manteniendo que las causas para hombres o mujeres son las mismas. Las teorías de redes, a su vez, se centran en las relaciones interpersonales de los inmigrantes pero tratan las redes como neu- 
trales desde la perspectiva de género (Massey et al., 1987). Para una revisión de las aportaciones realizadas en género y creación de redes, señalamos autores como Ehrenreich y Hochschikld 2002; Gamburd 2000; George 2005 y Suárez Navaz 2005.

Little (1973) y Moore (1991) rescataron los aspectos sociales implicados en la inmigración y el género. Pusieron de manifiesto las dos esferas representadas en esta teoría: la privada y la pública. En tanto que el hombre representa una migración laboral, la mujer se enmarca en la esfera de lo privado, de lo familiar, asociando su migración a una prolongación de sus roles reproductivos, o a factores de tipo social (viudedad, embarazos prematrimoniales, separaciones y rupturas, etc.), que contrastan con los factores económicos, productivos, asociados al hombre.

Castles y Miller (2004) identificaban al final de la década de los 90 una tendencia a la feminización de las migraciones internacionales como una de las características clave en el cambio del paradigma migratorio. Kofman y England (1997) por su parte, señalaban el considerable aumento de la feminización de las migraciones. Por un lado, y como apuntan (Raijman et al., 2003), se trata de la creciente necesidad de personas en el servicio doméstico, en las sociedades industrializadas, y por el otro, "la migración es una solución importante a los problemas de las mujeres dentro de un sistema económico y global" (England y Stell, 1997, p. 172).

A partir de los estudios pioneros, proliferaron los análisis que clarificaron la naturaleza de la economía política internacional que atrae a mujeres de países menos desarrollados en el servicio doméstico en todo el mundo. En España, el Estado y el mercado son co protagonistas de la feminización de los flujos: El Estado a través de la política de inmigración articulada por las prácticas institucionales que fijan la entrada y la inserción de los flujos en función de la gestión de grupos migratorios. Y el mercado, a través de una estructura de la demanda en función de las necesidades de las mujeres empleadoras del servicio doméstico, pertenecientes a las clases medias urbanas.

No obstante, existen escasos trabajos que consideren el papel de las migraciones femeninas (Gil, 1998, Pedone, 2005, Oso, 2008). A su vez, el servicio doméstico orientado hacia las migraciones internacionales comenzó a desarrollarse en la década de los noventa, cuando España se transformó en país de inmigración. El espectacular aumento de mujeres inmigrantes procedentes de países periféricos para llevar a cabo el trabajo reproductivo en los países centrales, viene determinado por el advenimiento de la ciudad global, la división internacional del trabajo y supone un trasvase de desigualdades de clase y etnia desde las mujeres autóctonas cualificadas que se incorporan al mercado laboral 
hacia las mujeres inmigrantes, que precisan ingresos económicos y se ven obligadas a dejar sus familias en los países de origen y a desatender sus propias cargas reproductivas (Parella, 2003). Oso advierte que las mujeres autóctonas utilizan fórmulas mercantilistas de reproducción ante la ausencia de políticas familiares que les faciliten el cuidado de los hogares. Se vuelve a reproducir el vínculo entre un mercado muy segmentado y un débil régimen de bienestar. Ante dichos vacíos, las mujeres autóctonas miran hacia la inmigración internacional para resolver las ausencias en la esfera reproductiva (Oso, op. cit.).

El nexo entre inmigración y envejecimiento comenzó a analizarse, recientemente desde una perspectiva asistencial. Desde la esfera pública, se desarrollaron estudios en España para diagnosticar la situación de los mayores, en relación con la Ley de Dependencia, pero no son muy abundantes los que han analizado las aportaciones de los inmigrantes como cuidadores (IMSERSO, 2005). Algunas aportaciones ahondan no tanto en el mercado informal como en sus condiciones y relaciones con las organizaciones sociales (Martínez Bujan, 2006). Desde otro punto de vista, ha sido más frecuente encontrar referencias a estudios enfocados a determinados grupos nacionales que tienen clara implantación en el trabajo doméstico, derivando una ligera atención a los cuidados de mayores (Escrivá, 2000; Colectivo IOE, 2001). Sin embargo, el campo está abierto, sin investigar apenas y por ello sin ofrecer las estrategias necesarias para solucionar el "desencuentro" provocado por la precariedad laboral de las inmigrantes por una parte, y la falta de profesionalización necesaria para este tipo de trabajo, por la otra (Gallart, 2007).

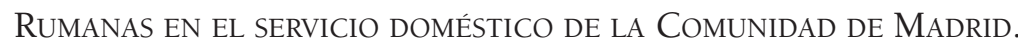
SITUACIÓN DE PARTIDA

La inmigración rumana en el servicio doméstico madrileño tiene poca tradición, pero se ha desarrollado de un modo muy importante en los últimos años, después de la apertura del espacio de libre circulación de personas para Rumania (2002). Coincidiendo con el inicio de la gran inmigración de origen rumano, se firmó un Tratado 7 entre los dos países, que tenía como finalidad ordenar los flujos migratorios de aquel país en España. Y si el mismo favoreció

7 El día 23 de enero de 2002 se firmó el Acuerdo entre el Reino de España y Rumania, relativo a la regulación y ordenación de los flujos migratorios laborales entre ambos Estados.

http://extranjeros.mtas.es/es/normativa_jurisprudencia/Internacional/migratorios/acuerdo_ Espana_Rumania.pdf [Acceso, 23 de Mayo de 2008]. 
la contratación en el origen en varios sectores de actividad como la agricultura o el sector de la construcción, no ocurrió lo mismo con el servicio doméstico que todavía no goza de una regulación en España. Al tratarse, pues, de un nicho laboral necesitado de mano de obra, por una parte, y de una población femenina en busca de nuevas oportunidades de ganancias por la otra, el encuentro informal entre dos mundos se produjo de manera benéfica para las dos partes implicadas. En paralelo, se desarrolló el sistema de redes de inmigrantes. En el caso rumano, la red se "mueve" continuamente, en una dinámica circular, tratándose de la ya conocida migración circulatoria. Se crearon prácticamente dos redes laborales importantes: una masculina, referida al trabajo en el sector de la construcción, y una red femenina llamada "red de las limpiadoras domésticas" (Sandu, 2006).

Y si en el año 2008, desde Rumania, siguen emigrando más hombres (un $55 \%$ ) que mujeres, el porcentaje de éstas, aumentó entre 2002 y 2008, desde un 36,16 hasta un $44,27 \%^{8}$. Estas son las cifras oficiales, pero la mayor parte de ellas, ni siquiera están registradas en el Padrón Municipal. Por tanto, señalamos una creciente feminización de la inmigración rumana en España.

La motivación de las mujeres que emprendieron desde Rumania su proyecto migratorio, su capacidad y empeño para poner en juego sus recursos personales y establecer estrategias que les permitan superar los obstáculos del camino, son elementos que están, necesariamente, vinculados a su situación personal, familiar, social y económica en su país.

Las inmigrantes ocupan, pues, el espacio transnacional. Según Glick et al. (1992:1), "sus vidas traspasan fronteras nacionales y comparten dos contextos socioculturales en un solo campo individual de experiencias sociales".

Fue, ciertamente, un lento despertar el de la mujer rumana. Pero a diferencia de la mujer española, o de la mujer latinoamericana, la rumana tenía la experiencia de la incorporación en el mercado laboral. Conocía desde la época dictatorial $^{9}$ el significado de ser empleada y, al mismo tiempo, cuidar a su familia. Después de las transformaciones registradas, el patrón ha cambiado, y su desper-

\footnotetext{
8 Instituto Nacional de Estadística, 2008. www.ine.es.

9 En la época de la dictadura rumana 1965-1989, las mujeres fueron continuamente discriminadas mediante una política muy férrea de fertilidad. Las que no se casaban hasta los 25 años, tenían la obligación de pagar al Estado una cantidad de mensual. Se pagaba otra cantidad, si el matrimonio no tenía hijos. Sólo se libraban de las tasas, las mujeres que tenían tres o más hijos. Cada año, las mujeres en edad fértil pasaban pruebas ginecológicas realizadas en presencia de la policía. Era esa, la política demográfica de Nicolae Ceausescu. Con la caída del régimen, se produjo la liberación de la mujer rumana.
} 
tar se debe al nuevo enfoque sobre su vida familiar, a la decisión de vivir su vida, más allá de la política, o del "qué dirán". La mujer aprende a tomar sus decisiones: casarse o no, tener hijos, divorciarse o separarse (Muresan, 1999).

"Pues claro que me fui. Acababa de divorciarme, tenía 27 años, una buena edad para volver a empezar. Cogí la maleta... No tuve hijos en mi fracasado matrimonio. Mejor para todos".

(Mujer, 43 años)

En su mayor parte, las entrevistadas destacan el hecho de que en España ya tenían a familiares y amigos establecidos a lo largo de los últimos años, hecho que les ayudó en la toma de decisión.

"¿Y por qué vine a España? Porque mis hijos mayores se afincaron aquí, la hija pequeña deseaba mucho estar junto a sus hermanos, y como yo estoy divorciada, también quise vivir con todos ellos".

(Mujer, 51 años)

En España existe cierta coincidencia general en señalar que el nivel formativo de los inmigrantes rumanos es alto. Esto procede de la etapa anterior al 1989, en la que el nivel de exigencia era muy superior al actual y la inserción educativa y universitaria también. No obstante, es cierto que los inmigrantes que han llegado a España, a la Comunidad de Madrid, en los últimos años, no son los que tienen el nivel más alto de formación (Pajares, 2007).

En el caso aquí analizado, se puede señalar que en su mayor parte, se trata de personas con estudios secundarios y de bachillerato.

"Tengo el Bachillerato, en el sector industrial. No he ido a la Universidad... no estudié lo bastante, es mi gran problema... Con estudios superiores es más fácil, sobre todo ahora, que tanto se piden... si no los tienes, es difícil encontrar un trabajo más o menos decente".

(Mujer, 37 años)

Existen casos en que las inmigrantes después de terminar los estudios de bachillerato, y al no encontrar empleo, se especializaron en formación profesional para encontrar un puesto de trabajo en su país, antes de iniciar el proceso migratorio.

"Estudié el Bachillerato, más tres años de Escuela Profesional en el sector de peluquería... de hecho trabajé allí de peluquera, es mi especialidad. Cuando empecé a estudiar, nos dijeron que si escogeríamos en vez de ir a la Universidad una formación profesional, se nos ofrecía un puesto de trabajo. Y me lo ofrecieron, pero con $100 €$, y sola con un niño ya no se podía".

(Mujer, 37 años) 
La llegada a España y a la Comunidad de Madrid significó para las mujeres una importante ruptura en su trayectoria laboral (Méndez, 2008). Se trata de un abanico de perfiles, pero interesa distinguir entre el nivel educativo y la experiencia profesional que tenían antes de llegar a España.

En la muestra seleccionada, hay jóvenes que no tenían un empleo o que no conseguían encontrar un lugar en el mercado laboral, mujeres de mediana edad, amas de casa, trabajadoras en varios sectores de actividad que abandonaron su universo laboral y vital para insertarse en otro, siempre con el mismo fin: mejorar sus ganancias y su modo de vida. Su formación es, pues, inadecuada para el mercado laboral español, sin experiencia por no haber trabajado o por haberla perdido.

"Empecé en una fábrica textil, con 16 años. Luego terminé mis estudios de bachillerato y tomé clases de canto popular. Más tarde, como me di cuenta de que en la industria textil era difícil y me afectaba la voz, encontré trabajo en la fábrica de chocolate de Brasov, donde trabajé durante los últimos 30 años de mi vida. También realicé un curso internacional de masajista, de relajación y masaje deportivo".

(Mujer, 50 años)

Las entrevistadas desempleadas fueron también candidatas a la emigración, y muchas de ellas emigraron con la desesperación del que no tiene a qué agarrarse, con la sensación de que el poder político de su país no era capaz de diseñar estrategias de ayuda, formación y recolocación después de los grandes procesos de privatización y reestructuración de las empresas.

"Sí... Ya sabe que durante la época de Ceausescu todos teníamos trabajo. También trabajé en un combinado químico. Tras su caída, cuando todo terminó, me metí de vigilante en el metro. Durante un tiempo fui ama de casa, otra forma de decir que me quedé sin empleo... Luego nos fuimos...".

(Mujer, 37 años)

"Trabajé... 11 años en el sector de la electrotécnica... después de la revolución, la reforma, la privatización... Me quedé sin empleo. Además, nació mi hija justo aquel año, en 1989, fue muy duro Y luego tuvimos que hacer algo, porque sólo con un empleo no podíamos salir adelante... Abrimos una sociedad comercial... vendías en el rastro... ropa, calzado... fue muy difícil, porque nunca pude trabajar en mi sector... quise abrir un negocio... Y allí, en el mercado fue difícil porque siendo la gente pobre, la venta no funcionaba... y luego decidimos hacer otra cosa, algo más importante. Y entonces fui yo la que dije que me iría fuera, a buscar nuevas oportunidades".

(Mujer, 38 años) 
SERVICIO DOMÉSTICO Y CUIDADO DE MAYORES EN MADRID: UN NICHO LABORAL CUBIERTO POR NECESIDADES ENCONTRADAS

Las posibilidades de inserción en el mercado en la Comunidad de Madrid, se reducen, para los inmigrantes, a espacios laborales delimitados por el contexto de recepción (Portes y Böröck, 1989). En este marco confluyen una serie de factores, entre ellos, la propia legislación de extranjería, que limita tanto las posibilidades laborales de aquellas que no logran tener un permiso de trabajo y residencia -condenadas al mercado sumergido- como de aquellas que sí lo consiguen -limitación territorial y de ámbito laboral durante el primer año. Esta variable no hace sino acentuar y legitimar las propias tendencias de un mercado segmentado en el que la demanda de mujeres extranjeras se produce en ciertos sectores, como el trabajo doméstico o de cuidado de personas mayores.

Un 80\% de las mujeres inmigrantes rumanas que trabajan en España, son empleadas de hogar, en régimen de interna o de externa, con su variable por horas.

\section{Búsqueda de empleo. El papel de las redes de inmigración}

En la búsqueda de empleo, las inmigrantes se enfrentan a un cúmulo de obstáculos, vinculados a su doble condición de ser mujeres e inmigrantes. Esta realidad es la que autoras como Monica Boyd (1984) o Saskia Sassen (1984) han denominado "doble negativa o desventaja" y que investigadoras como Mirjana Morokvasic (1984) ya denominan "triple discriminación" como resultado de la articulación de múltiples procesos de discriminación, en base al género, a la discriminación racial, de etnia y a la explotación.

La ingente marea de inmigrantes rumanas, tras romper los lazos férreos de su pasado, indagaron en la realidad española con la fascinación del que descubre una nueva existencia, sin pensar en desventajas o discriminación. Querrían encontrar una nueva vida. Ellas desarrollaron en el tiempo y en el espacio, el laberinto de su obra inicial, tejiendo relaciones entre el origen y el destino, creando la movilidad, haciendo que los espacios se muevan, respiren, se dinamicen (Marcu, 2008). De esta manera se creó la red informal que centró sus estrategias en optimizar las posibilidades y la capacidad de decisión de las inmigrantes en el principal nicho laboral adjudicado en el destino: el servicio doméstico.

En comparación con la situación de la mujer latinoamericana, con una cierta tradición en el empleo doméstico y de cuidados, la mujer rumana tuvo 
que ganarse el derecho de iniciar la creación de la red. Y lo hizo, a base de constancia, y de su capacidad de superar las dificultades. La red rumana está formada por trabajadoras irregulares, rotativas, que ocupan, muchas veces, el mismo puesto de trabajo que dejó otra amiga o familiar.

"Me ayudó una amiga, que había trabajado allí. Me dio el número de teléfono de la señora, llamé, y me dijeron que sí, que podría ir a trabajar a pesar de que no sabía hablar nada de español, pues sólo podía decir "hola" y... entrando en su casa, me aceptaron, y empecé a trabajar desde aquél día".

(Mujer, 29 años)

El criterio fundamental de selección aplicado por las empleadoras no es la cualificación profesional de la trabajadora sino las referencias que de la misma puedan ofrecer otras empleadas de confianza del entorno social, u otras empleadoras próximas. Las redes contribuyen de esta manera a una cierta regulación o control de este sector informal. En este sentido, actúan en el mercado de trabajo ofreciendo beneficios tanto a la demanda de empleadas como a las mujeres integrantes de la red. Así, por ejemplo, cuando una mujer empleada en el servicio doméstico salga de vacaciones, o tenga que volver a Rumania para realizar cualquier trámite será ella quien recomiende a otra mujer y organice la sustitución durante dicho período. Es muy habitual que el reemplazo se aproveche para facilitar la inmigración de otra mujer que se encuentra todavía en el país de origen.

"Y un día llegué aquí, sin enterarme de nada. Mi hermana se fue a casa, porque su marido tenía un problema gordo, y me dijo: por qué no te vienes tú en mi lugar porque así no perdemos el trabajo. La señora te empleará, me dijo, porque estamos como en la familia. Y sí, la señora me empleó, es muy maja. Me quedaré hasta que mi hermana solucione su problema, luego ya veré. Pero a mí me viene muy bien, porque así, gano un dinerito".

(Mujer, 37 años)

La migración en red no favorece la regularidad, tampoco la integración en la sociedad de acogida, pero lo que persiguen las inmigrantes es trabajar el tiempo necesario, cumplir los objetivos iniciales vinculados a la mejora del nivel de vida en su país de origen.

"Quiero aguantar un poco más, un año, máximo dos, hasta que mis hijas acaben sus estudios. Luego vuelvo a mi país. Por ahora, no pasa nada si me toca librar solo los domingos. Así gasto menos".

(Mujer, 48 años)

Estudios Geográficos, Vol. LXX, 267, pp. 463-489, julio-diciembre 2009 ISSN: 0014-1496, eISSN: 1988-8546, doi: 10.3989/estgeogr.0474 
Tras la intervención de la red, las reglas del juego se establecen privadamente, se diseñan entre la familia y la inmigrante. Las condiciones del trabajo, las particularidades, los cuidados específicos, las horas, los días libres, el salario, son el objeto de una conversación privada e íntima en la que se encuentran solas ambas partes. En este sentido, según Anderson, (2000), quien emplea, adquiere algo más que el producto del trabajo de la empleada; "compra" a la persona en su totalidad, sobre todo, cuando se trata de la modalidad del servicio doméstico interno.

Y el mayor problema en este encuentro inicial, que destacan las inmigrantes rumanas, es el desconocimiento del idioma español.

"Porque la primera pregunta que te hacen cuando quieres acceder a un puesto de trabajo es: “¿Sabes hablar español?” Y tú, si no sabes, ¿qué haces? A la fuerza, tienes que decir que sí, e intentarlo. Porque en el servicio doméstico el idioma es muy importante. Si cuidas niños tienes que comunicarte con ellos, por si enferman; si cuidas mayores, más todavía... porque tienes que darles las medicinas, sacarles, lavarles, y para todo hay que hablar con ellos. Vamos ¿cómo pretender que te contraten si no sabes hablar nada de su idioma?".

(Mujer, 29 años)

\section{SituACIÓN LABORAL COMO EMPLEADA DE HOGAR Y CUIDADORA EN ESPAÑA}

En ausencia de un convenio para las empleadas domésticas, las condiciones laborales en este ámbito se remiten exclusivamente al Real Decreto Regulador del Servicio al Hogar Familiar (R. D. 1.424/1985). Por lo general, las inmigrantes prefieren cuidar niños, aunque, la demanda de cuidadores de personas mayores, aumentó últimamente.

Las personas cuidadas, a menudo son muy mayores, viven solas, y en algunos casos padecen un deterioro psíquico tal como el Alzheimer, o que están parcialmente inmovilizadas o encamadas. El trabajo remunerado en el ámbito doméstico se realiza, sobre todo, de forma sumergida. Para las inmigrantes sin papeles, sin conocimiento del idioma, el acceso, además de ser relativamente sencillo ofrece una mayor seguridad que emplearse en otros ámbitos.

"Desde el primer día que entré en su casa para la entrevista, me dejaron bien claro que no me harían contrato de trabajo... Pero como yo acababa de venir, tampoco entendía bien el idioma, tampoco podía pedir mucho. Lo que quería era trabajar... si no, no podíamos pagar la casa, ni comer mi marido y yo... así que ya dejamos de hablar del contrato. De hecho, nos entendíamos mal, muy mal, por culpa del idioma, o sea... yo hablaba rumano e italiano, ella español".

(Mujer, 48 años) 
El trabajo se realiza básicamente en dos modalidades: el de trabajadora interna y el de externa (trabajadoras a jornada completa y por horas). Las inmigrantes que se incorporan a este ámbito trabajan habitualmente primero como internas, hasta que después de uno o varios años logran dar el salto a la modalidad externa, aunque algunas permanecen como internas durante mucho tiempo. Cada modalidad ofrece ventajas y desventajas que las mujeres sitúan en una balanza, junto a sus necesidades personales y familiares, y siempre en relación a sus posibilidades en el mercado y al resultado que pretenden obtener de la experiencia migratoria.

\section{Entre la necesidad y la explotación: Trabajadoras en régimen de interna}

Autoras como Young (1990) consideran el servicio doméstico en su modalidad interna, como un ejemplo claro de explotación, a través del cual, se produce una transferencia de los resultados del trabajo de un grupo en beneficio de otro, lo que comporta distribuciones desiguales de recursos y de riqueza.

No obstante, el empleo en la modalidad interna, es preferido por la mujer rumana que necesita obtener ganancias inmediatas, aún sin conocer el idioma español. Si la red funciona, se le suele aceptar sobre todo, cuando se trata de un trabajo difícil, con una persona mayor dependiente, muy enferma. En estos casos, lo más urgente para las dos partes es que el trabajo comience a desarrollarse, por el bien común: para la inmigrante, porque está en un lugar seguro a pesar de estar indocumentada, y para la familia, porque necesita que alguien atienda la casa y al potencial enfermo, o a los niños.

Prácticamente no se habla de la necesidad de un contrato laboral para la empleada.

"Nunca me dijeron que me harían un contrato... Además, acababa de venir de Rumania y no sabía, entendía algo, pero no podía hablar. Mi situación era, además, ilegal, por tanto no podía trabajar en cualquier sector, no me hubieran aceptado y estuve obligada por las circunstancias creadas, a aceptar este trabajo. Además, como no tenía que pagar el alquiler, no tenía que pagar la comida, dije que sí... En esta situación, la policía no sabía nada de mi existencia”.

(Mujer, 44 años)

Trabajar en régimen de interna supone la pérdida del espacio y tiempo necesario para mantener una vida privada al margen del trabajo, al menos durante los días laborales. La permanencia obligada en el lugar de trabajo, así como la convivencia continua con la familia, son las condiciones laborales 
más difíciles de asumir para las trabajadoras en esta modalidad. Varias entrevistadas describen esta experiencia como un "encerramiento", una "penitencia", aludiendo a la carga psicológica que supone el aislamiento social en un hogar que no es suyo.

"A veces estoy triste, porque estoy lejos de casa, penitente... no puedo salir cuando quiero. Vivo en una cárcel de lujo...".

(Mujer, 40 años)

El horario se define no por las horas de trabajo sino por las de libranza, un hecho facilitado por la definición del horario establecida en la regulación del servicio al Hogar familiar. En la mayoría de los casos, la trabajadora entra en el domicilio en el que trabaja, el domingo entre las 20 y las 22 horas, y excepcionalmente, el lunes a primera hora. En muchos casos, el acuerdo incluye dormir todas las noches (inclusive la del sábado a domingo, cuando hay niños o personas mayores) y el domingo, si tienen el día libre, servir el desayuno a la familia antes de salir. Así, se incumple el período de día libre (de mínimo 24 horas) de libranza continuada una vez a la semana. (R. D. 1.424/1985). Tampoco se cumple siempre lo establecido en la regulación respecto a ocho horas de descanso entre una y otra jornada laboral, ya que, en algunos casos es necesario atender a las personas ancianas y enfermas durante las noches con la consiguiente acumulación de cansancio.

"Trabajo para una señora de 79 años, con parálisis en la parte izquierda de su cuerpo, con lo cual, depende totalmente de mí... con un horario imposible... Me levanto a las cinco y media de la mañana, para llevarla al baño... lavarla, vestirla... Y todas esas cosas no son un problema para mí, no superan el límite, es normal... El tema es el control continuo de la familia... Me dejan salir fuera de la casa solo una hora a diario, y el día tiene 24 horas... hay que salir a respirar, al menos dos horas diarias...".

(Mujer, 48 años)

Hay una escasa definición de las funciones a realizar por la empleada. Los contratos son habitualmente verbales, y cuando se establecen, normalmente, solo se define el salario o el tiempo libre. Las empleadas internas entrevistadas trabajan todo el día, sin definición alguna de sus tareas, y aún cuando existe, las personas empleadoras tienden a aumentar y diversificar las mismas según su conveniencia.

Las empleadoras reclaman a la trabajadora que esté dispuesta a realizar cualquier tipo de función, hasta el punto de que, en ocasiones, se delegan en esta empleada responsabilidades familiares que no le corresponden. 
En el caso de las cuidadoras, se trata de trabajos de importante intensidad física -mover a las personas con deficiencias físicas y sobre todo psíquicas.

"Es una señora mayor, que tiene Alzheimer. Ella no se da cuenta de nada, dice que está perfectamente. No quiere ni levantarse, ni vestirse, ni comer. Le caliento la comida... se la doy. Es muy difícil hacerla comer. Le engaño, le digo cosas, se necesita mucha paciencia... También es una lucha quitarle la ropa de calle. Nunca quiere cambiarse de ropa... A veces, son las cuatro de la tarde, y la señora no quiere comer, no quiere cambiarse... No estoy preparada, no...”.

(Mujer, 41 años)

Las inmigrantes entrevistadas no tienen formación para cuidar enfermos o mayores, pero se les emplea igual, porque, los beneficios son mayores. Y aunque se prefieran más las inmigrantes latinoamericanas por el dominio del idioma, porque fueran "más dulces, más sumisas más adecuadas" para los trabajos domésticos, (Izquierdo, 2003), las rumanas han ido ganando terreno.

La variabilidad en los salarios es importante, aunque generalmente se sitúan entre los 600 y los 800 euros mensuales. Las inmigrantes recién llegadas aceptan salarios inferiores (600-700 euros) mientras que aquellas que llevan más tiempo y conocen los precios del mercado y la demanda existente establecen ellas mismas su precio mínimo entorno a 750-800 euros. Un factor valorado por la demanda de trabajadoras domésticas es la edad de la empleada. La preferencia por mujeres de mediana edad le permite a éstas establecer su salario mínimo en 800-850 euros, mientras que las jóvenes de menos de 30 años, menos cotizadas, no superan, habitualmente, los 700 euros mensuales. Para las inmigrantes procedentes de Rumania, estos sueldos, al menos al principio representan una satisfacción, pues, en su país, no ganaban más de 100 euros al mes. Y aunque vivan una situación difícil, las inmigrantes saben que al menos, pueden realizar envíos de dinero a casa, para ayudar a sus familias.

"Es un infierno, pero sé que saldré de él... Porque todo pasa y si ahora puedo pagar la matrícula a mi hija, estoy contenta".

(Mujer, 44 años)

Emprender "el vuelo" tras la prueba de supervivencia inicial: Trabajadoras en régimen de externa y por horas

En la mayoría de las ocasiones, el trabajo de externa suele constituir un segundo peldaño en la experiencia como empleadora doméstica. Superado un 
tiempo (que suele variar entre 3 meses y dos años) en la condición de trabajadora interna, después de traumas psicológicos, situaciones límite, cuando se realiza algún tipo de reagrupación familiar (marido, hijos), se suele emprender el "vuelo". Para la búsqueda de un trabajo de externa, funciona también la red, aunque las entrevistadas recurrieron, asimismo, a las Asociaciones de Inmigrantes, empresas de colocación, anuncios en periódicos, a través de carteles fijados en tablones de anuncios, o por toda la ciudad.

"Vino mi marido y tuve que dejar el trabajo de interna para estar juntos. Me ayudó una amiga a encontrar estos dos trabajos de externa. Y gano más, pero estoy todo el día fuera de casa. Salgo a las cinco y media y llego a las diez de la noche, sólo para dormir".

(Mujer, 40 años)

El factor tiempo se convierte en protagonista para esta modalidad del servicio doméstico. En el lado positivo, la principal ventaja supone disponer de un tiempo propio para desarrollar una vida privada al margen del trabajo. La trabajadora puede convivir a lo largo de la semana con personas distintas a las empleadoras. Para aquellas que han dejado a sus hijos en el país de origen, y que logran alquilar un piso, se abre la posibilidad de reagrupación familiar. La decisión de abandonar el empleo de interna para buscar trabajo como externa se produce a menudo en estas condiciones, pero también, cuando las propias circunstancias de las mujeres inmigrantes han cambiado.

"Me ofrecieron la posibilidad de tener una beca para estudiar español, en una Universidad, así que, a pesar de no tener empleo seguro cuando abandoné la casa en la cual trabajaba de interna, dije que sí, porque estaba en juego mi formación, y mi futuro. Luego, encontré el trabajo por horas que tengo ahora, y que me permite compatibilizar mis estudios con el trabajo".

(Mujer, 29 años)

En el lado negativo, se sitúa la falta de tiempo o el cansancio producido a lo largo de la semana. Otras desventajas se vinculan a una mayor inseguridad laboral, y, sobre todo para aquellas que no consiguen un empleo de jornada completa, a la necesidad de pluriemplearse. Las "externas" han de asegurarse una cierta "clientela" para reunir un sueldo al menos equivalente al de una "interna". Algunas logran trabajar las mañanas en un hogar y las tardes en otro, pero la mayor parte tiene que asumir un gran número de pequeños empleos que pueden llegar a ser tan breves como una hora en un hogar, para levantar y lavar a una persona mayor, y otra media hora/una hora por las noches para acostarla. 
"Trabajo en varias casas. Pero en una tengo que ir dos veces al día: media hora por la mañana para levantar a un señor mayor, y media hora por la noche para acostarlo. Menos mal que no viven lejos de mí”.

(Mujer, 46 años)

Es muy habitual que las trabajadoras externas combinen trabajos en domicilios con trabajos de limpieza en otros sectores (hostelería, clubs de fútbol) sobre todo durante el fin de semana.

"Los martes y los jueves trabajo en una casa, y los lunes y los miércoles en otra. Por las tardes trabajo como limpiadora en un club de fútbol y allí, también hago de camarera los sábados y los domingos cuando hay partido".

(Mujer, 29 años)

Dependiendo del acuerdo laboral, el horario se ajusta a las ocho horas diarias, pero en ocasiones las supera hasta alcanzar a 10-11 horas.

"Trabajo desde el primer día limpiando casas por hora. A veces, me hago un lío, porque son 9 casas las que tengo, ni más, ni menos. Pero tengo suerte, salvo los sábados que me pilla más lejos. Porque las demás casas están todas cerca. Y las señoras son buenas. Bueno que de papeles ni hablar, pero ya no me importa. Me salen las cuentas a fin de mes".

(Mujer, 46 años).

Las trabajadoras externas realizan una gran variedad de funciones, desde llevar niños a colegios, planchar, cuidar mayores, personas con deficiencias físicas o psíquicas, hasta todo lo que supone la limpieza del hogar. Su salario se sitúa en torno a 600-65010 euros al mes, y el precio de las horas sueltas oscila en términos generales entre siete y nueve euros.

"Por la mañana llevo una niña al colegio, que traigo por la tarde, cuando le doy la merienda y limpio la casa, hasta que llega su madre. Pero mientras tanto, voy a otra casa, donde sólo tengo que duchar a una señora mayor, y limpio por horas otras dos casas".

(Mujer, 53 años)

"Porque las españolas trabajan por $10 €$ la hora, y a nosotras se nos pagan con 8 y tenemos que estar contentas, porque a la mayoría se les paga con $7 €$. Y el trabajo es duro... Y cuando vas a la entrevista, la señora te dice claro que no puede darte más, y entonces tú te quedas, porque a ver, dónde vas tú, que apenas hablas

\footnotetext{
${ }^{10}$ Hay inmigrantes que suelen llegar a 1.000 euros Por media jornada se gana alrededor de 400 euros.
} 
su idioma... y es que es así. Vamos que a mí, en las dos casas me pagan $8 €$ la hora...".

(Mujer, 29 años)

\section{AMARGA SATISFACCIÓN: VALORACIÓN DE LAS INMIGRANTES SOBRE SU TRABAJO COMO EMPLEADAS DE HOGAR Y DE CUIDADOS}

Las inmigrantes observan, experimentan, perciben y valoran su situación, a través de las lentes que constituyen su modo de entender y construir su relación con el trabajo. En primer lugar, desde su posición de extranjeras, se enfrentan al mercado laboral, visualizan e interpretan las circunstancias que las rodean, perciben sus limitaciones y potencialidades para encontrar trabajo en este mercado.

Aparecen dos factores que adquieren una enorme relevancia a la hora de valorar la satisfacción de las inmigrantes sobre todo de las que trabajan en la modalidad de interna: en primer lugar, el trato recibido y en segundo lugar, si cuidan mayores, la carga psicológica producida por el hecho de tener que atender durante casi las 24 horas del día a una persona anciana, sobre todo si padece algún trastorno de senilidad.

"Si se levanta por la noche, me despierto, porque hay noches cuando no duerme. Lleva como tres semanas sin dormir... le tengo que llevar al baño, que lavar de noche... Es muy difícil, porque es una persona muy nerviosa. Sobre todo cuando le tenemos que cortar las uñas... Mire, ¿ve usted?: Aquí me salió un moratón... Tiene fuerza como para cinco personas... Cuando se pone irascible, soy la única que consigue tranquilizarlo...".

(Mujer, 44 años)

El ámbito doméstico es un espacio socialmente invisible, y por ello especialmente vulnerable a que se produzcan malos tratos. Algunas entrevistadas han tenido que soportar humillaciones y desprecios por parte de empleadoras, una situación dura sobre todo para las internas que tienen que aguantar la explotación toda la semana.

"Puede irse al baño, pero sólo cuando quiere. Si me quiere hacer daño, no va al baño. Porque me toca a mí lavarla, cambiarla. Y si le da hacer esto tres veces al día, pues me lo hace. Y para mí es muy duro... Porque se va al baño, grita, y empieza a tirarlo todo por las paredes... Y parece que tiene bien la mente, y esto me hace pensar que lo hace para que yo sufra, para hacerme daño, porque luego me toca calmarla, quitarle toda la ropa, tranquilizarla para poder lavarla, secarla, y ponerle 
ropa limpia. Y luego limpiar las paredes, y el suelo... y me pongo a llorar, porque sé que no me merezco esto, y tampoco la puedo dejar sucia".

(Mujer, 51 años)

Las entrevistadas que han tenido este tipo de experiencia estaban a punto de abandonar el trabajo, o al menos lo pensaban hacer pero no sabían hacía dónde ir. Su propia salud estaba en juego.

Las condiciones laborales de la mayoría de las inmigrantes les obligan a poner en suspenso su propia vida, ya que apenas disponen de espacio y tiempo para llevar adelante sus responsabilidades familiares. Sus relaciones personales a lo largo de la semana se ven reducidas, pues, al contacto telefónico con familiares y amistades tanto en Madrid, como en su país. Pero aún así, están contentas por poder enviar dinero a sus hijos.

"Lloro, pero estoy contenta porque con este dinero que ahorré lo mandé a mis hijos, porque soy viuda, desde hace quince años... y saqué adelante a mis hijos... y con la situación tan mala de los sueldos en Rumania... ellos me necesitaron, y yo les tuve que ayudar. Les ayudé cuando se casaron, ya sabe lo difícil que es ahora organizar una boda... Les compré mis regalos, tal como pude... Arreglamos la casa del pueblo, y yo cuando quiero volver, tengo adonde volver".

(Mujer, 61 años)

Parte de las entrevistadas aceptan estos períodos muy difíciles de sus vidas, para mantener a sus hijos en la Universidad, en sus países de origen.

"Porque mis hijas son estudiantes. Una tiene 23 y la otra 20 años, y tengo que pagar dos matriculas y más tasas para la Universidad... Al menos, que tengan ellas un futuro mejor, que no trabajen como yo de criada".

(Mujer, 51 años).

Pero también lo hacen para los hijos que se quedaron a vivir con los abuelos, o con los padres. Puesto que no les pueden ayudar ofreciéndoles una educación y el cariño, tan necesario en la edad de crecimiento, contribuyen económicamente al bienestar de sus hijos.

"Mando a mis hijos que viven con sus abuelos, para que coman, para que tengan ropa y para que saquen sus estudios adelante. Ya pronto irán a la Universidad. No les puedo dar cariño, pero sí, 200 euros al mes, para que salgan adelante. Y si hace falta quedarme aquí hasta que ellos acaben las carreras me quedo, y así, ya no tendrán que fregar ellos casas, con títulos universitarios...".

(Mujer, 48 años)

Lo que más valoran las cuidadoras inmigrantes, sobre todo las que trabajan en régimen de interna es tener aseguradas las necesidades básicas. Consideran 
que es un recurso importante para una "irregular", y si se les trata bien, incluso aprecian el trabajo, a pesar de no estar formadas para desempeñarlo. Por otro lado, el vínculo afectivo que crean con los niños, o con la persona mayor favorece una cierta integración de la cuidadora inmigrante en la familia.

“... Con el corazón se hacen las cosas, yo al menos, no puedo de otra manera. Y como se trata de una señora mayor, hay que contarle, decirle cosas, explicarle, contarle de nuevo. Pero lo sabía, porque, mi amiga que me dejó su puesto me dijo que, con el tiempo, llegaría a querer a esta señora, porque es una persona muy buena. Y le digo de verdad, es que no tengo ningún tipo de problemas...".

(Mujer, 50 años)

La satisfacción amarga se desprende de todos los discursos de las entrevistadas. El trabajo lo aceptan porque no tienen más remedio, no pueden aspirar a nada mejor, aunque se den condiciones de sobrecarga laboral, sin descanso. Algunas entrevistadas encuentran el salario bueno y valoran la dignidad del trabajo del cuidado, pero en general, esperan regularizar su situación para marcharse.

"En cuanto pueda, me voy. Necesito mejorar un poco el idioma, pero vamos, que en 2009, cuando podamos trabajar libremente, espero hacer algún curso e irme".

(Mujer, 37 años)

Las entrevistadas destacan la falta de valoración de su trabajo, lo que les hace percibirse como personas muy limitadas con respecto a sus posibilidades de poder acceder a otro trabajo, y una actitud de miedo y falta de apoyo que les impide romper y buscar nuevos caminos laborales.

"No me valoran nada... Aguanto porque no sé hacer otra cosa Mi generación... los que no sabemos de ordenadores... Es difícil. Ahora todo se hace por ordenador... Y antes el ordenador era sólo para la elite".

(Mujer, 48 años)

La cuestión de los sueldos bajos es relevante y da pie a considerar el trabajo doméstico como un sector más de paso que de destino. Ello parece verificarse en los discursos. Las mujeres son conscientes de que se les paga menos por su condición de inmigrantes. Es, pues, un trabajo valorado negativamente por parte de ellas, en el que "aguantan hasta encontrar algo mejor".

La insatisfacción está, asimismo, vinculada a la perdida de intimidad, en el caso de las entrevistadas que trabajan en la modalidad de interna.

"Es que tengo que dormir con la señora en la habitación. Yo no lo sabía... No me lo dijeron, me encontré con esa realidad. Y ella se acuesta muy temprano, a las diez. Tengo que apagar la luz, y a lo mejor me apetece leer y no puedo. Y luego, 
ella se despierta al día siguiente a las diez. Como usted comprenderá, yo no puedo dormir 12 horas, y si me levanto para ir al baño dice que la despierto...".

(Mujer, 44 años)

Pero todas coinciden que en su vida hubo cambios desde que iniciaron el proceso migratorio.

"Pues sí... hubo cambios... Mi personalidad, para empezar, sí... allí hay amigos, tienes vida personal, aquí... estás solo... y tu vida es el trabajo, nada más... Yo no tengo ningún día libre... Salgo de una casa para entrar en otra. Tampoco puedo ir al cine... pero puedo ver la tele una noche en la que no duermo... En fin, que la diferencia es enorme... Viví una ruptura terrible... otro mundo. Es otro país, otra cultura, otras costumbres... Mucha soledad... pero más dinero, y posibilidad de volver mejor a casa en el futuro".

(Mujer, 41 años)

Las trabajadoras aprenden, a través de este empleo, cuál es la verdadera condición humana del inmigrante: aislamiento, explotación, chantaje, desinformación y dependencia del empleador. La Organización Mundial de Trabajo llaman a estos fenómenos "esclavismo moderno"11, estimándolos como un negocio muy provechoso, con un valor de 15.515 millones de dólares a escala mundial. Los más frecuentes casos de explotación de los trabajadores de la Europa del Este, además del ya conocido tráfico de mujeres, una lacra para la sociedad, se dan en el servicio doméstico, cuidado de mayores o de niños.

"Sí, todo es dificultad. No hay ninguna facilidad, nada para mí... No puedo ni salir de casa, menos mal que tengo que sacar a la señora. Y llevar a los niños al colegio. Estoy muy cansada, porque por la noche, el niño que duerme conmigo en la habitación se despierta, llora... me duele el cuerpo y no puedo ir ni al médico, porque no tengo tiempo, y además, tampoco tengo tarjeta sanitaria. Muchos meses me dicen que no tienen el dinero para pagarme, y tengo que esperar... y tengo miedo de que nunca me lleguen a pagar...”.

(Mujer, 51 años)

Tampoco conocen sus derechos, viven aisladas con sus compatriotas y para quienes trabajen en régimen de interna, su vida depende de las familias que las emplean. Todo ello aventaja a los empleadores que, aprovechándose de la falta de información de las trabajadoras y de su miedo a quedarse sin trabajo, las explotan, pagándoles menos, infringiendo los más elementales derechos.

11 Informe OIT: “¿Ayudantes o esclavos? Comprender el trabajo infantil y doméstico y cómo intervenir" (Ginebra, 2004). 
"Porque la gente me pregunta: “¿Si estás tan mal, por qué no te vas? Pero es que nadie me ayuda... Y creo que volveré a mí país porque es mejor estar allí, pobre, con mis hijos, porque esta no es vida. Porque mis hijos no tienen ni idea de la humillación que vivo yo aquí. Y pido a dios que nadie se entere nunca más de mi vida aquí".

(Mujer, 51 años)

El recurso contribuye, pues, a mantener y aumentar la precariedad, tanto de las familias, que están atendidas pero por personal no especializado, como de las inmigrantes que se ven sometidas a un trabajo en el que no tienen tiempo libre, sin un contrato de trabajo formal, muchas veces cobrando sueldos bajos y con la difícil carga psicológica que supone trabajar en el servicio doméstico, cuidando niños o cuidar a una persona enferma, dependiente, sin los conocimientos necesarios.

Pocas entrevistadas desean la reagrupación familiar, sino más bien, regresar a su país, en cuanto pase el período de dificultades. Esto pone de manifiesto, una vez más, el hecho de que se trata de una inmigración laboral temporal, que coincide con el período de transición de Rumania hacia la economía de mercado, y que, a medio plazo llegará a su fin.

"Porque la voz de la sangre te tira, allí donde naciste... la gente... donde estudiaste, los vecinos, la familia. Porque a mí no me gusta estar aquí, pero lo necesito, porque necesito el dinero, es sólo esto: la necesidad. Creo que un $70 \%$ de los que ahora estamos por aquí, volveremos a casa. Porque no importa si te has realizado u no, si tienes una casa aquí, un piso, un trabajo, no importa, en ninguna parte se vive mejor que en tu país... Así veo yo las cosas...”.

(Mujer, 41 años)

\section{CONCLUSIONES ¿HACIA LA REGULACIÓN DEL MERCADO DEL SERVICIO DOMÉSTICO} EN ESPAÑA?

El sector informal de servicio doméstico vive una dinámica importante en los últimos años, desde que los flujos de inmigrantes entraron de modo masivo en la península. Bajo el "encuentro" de necesidades realizado entre la familia española y la inmigración, hay una serie de carencias imposibles de obviar en pleno siglo xxi: se trata de las precarias condiciones laborales en el mercado sumergido del sector. Por ello, es indispensable que se produzca un cambio radical que cuestione el sistema social y económico, que combata las desigualdades de género desde su raíz. Que se produzca una transformación de los imaginarios sociales; que se reconozca que los servi- 
cios de atención a la infancia y a las personas ancianas dependientes son de vital importancia.

Actualmente, se prepara un Decreto Ley que regula el Servicio Doméstico, y que tiene como fin realizar cambios en el sector, sancionando a los empleadores que empleen personas sin contrato laboral. Se trata de un proceso de integración del sector al Régimen General de la Seguridad Social.

La Plataforma Estatal de Asociaciones de Trabajadoras del Hogar' ${ }^{12}$ denunció la situación en la que se encuentra este colectivo. Entre sus reivindicaciones, se defiende el reconocimiento social por la labor que llevan a cabo las mujeres empleadas en este sector. Se rigen por un real decreto de 1985 que regula el régimen especial en la Seguridad Social al que están sometidas. El panorama resulta tan desolador que ni siquiera existen estudios o informes fiables que contabilicen el número real de trabajadoras que pertenecen a este sector. Lo que descubre otra realidad: el alto porcentaje, un 64\% de empleadas de hogar que se encuentran en la economía sumergida, es decir dos de cada tres $^{13}$. Y lo demuestra el hecho de que sólo 271.055 estaban dadas de alta en la Seguridad Social (en febrero de 2008), mientras que había 749.400 personas que trabajaban en esta actividad Como cabía esperar, el 91\% de este colectivo son mujeres, y un $68 \%$ de ellas son extranjeras -(las rumanas ocupan el tercer puesto después de ecuatorianas y colombianas) ${ }^{14}$.

Estas personas no cuentan con subsidios para el desempleo, no se les reconocen accidentes laborales y la baja por enfermedad es a partir del día 29, no desde el cuarto día, como para el resto de trabajadores. Pero todo esto, en el caso de que las empleadas tengan un contrato laboral. Porque las entrevistadas no cuentan con él. Hablamos, en este caso, de un acuerdo verbal, únicamente, que las convierte todavía más en personas desprotegidas y excluidas de la sociedad. Lo que se defiende en la Plataforma es que todas las mujeres que trabajen en el ámbito tengan un contrato por escrito que recoja una jornada laboral de 40 horas semanales con sus descansos.

La situación específica de la mujer inmigrante en el mercado laboral exige, además, medidas adicionales, encaminadas a eliminar la discriminación institucional respecto a los trabajadores en función de su nacionalidad. Cabe destacar la eliminación de los permisos de trabajo que están circunscritos únicamente a un sector de actividad y que frenan la movilidad laboral. Al

12 Entidad creada en España, en abril de 2008.

13 Informe Caritas: "La Campaña de las Empleadas de Hogar", (abril de 2008).

14 Según la Encuesta de la Población Activa de 2006. Encuesta de la Población Activa, 2006. [Disponible] <http://www.ine.es/> [Acceso 15 de Abril de 2008]. 
mismo tiempo, puesto que muchas inmigrantes rumanas disponen de un cierto nivel educativo, debería avanzarse en el reconocimiento de sus cualificaciones específicas. Es apremiante garantizar una oferta amplia de cursos formativos que afiancen la profesionalización en el sector.

Por cuanto al mantenimiento del recurso, creemos que a pesar de la regulación del Decreto Ley, el mercado informal tiene futuro en España.

Las mujeres inmigrantes de Rumania, a medio y largo plazo, dejarán de trabajar en este mercado, a medida que mejoren las condiciones de vida en su país, y puedan homologar sus estudios como ciudadanas comunitarias. Por ahora, seguirán en el nicho, porque es su única posibilidad para hacer frente a las dificultades creadas por la transición de Rumania hacia la democracia y la economía de mercado.

"No hay reconocimiento por parte del Estado rumano, y pedimos un poco más de consideración, porque nos quedamos sin trabajo, con hijos, sin un duro, y tuvimos que irnos a limpiar casas por el mundo... las mujeres, sí, las mujeres rumanas... que se les reconozca el mérito en su propio país... Porque ya está bien, queremos regresar, han pasado casi veinte años de sufrimiento... Porque las mujeres muchas veces se van, y dejan a sus hijos solos, con los abuelos, en el mejor de los casos... y nunca se sabe lo que puede pasar... Y aquí, somos unos extranjeros, ¿qué somos? Hoy estamos, mañana no...".

(Mujer, 40 años)

Se comprende la importancia de diseñar estrategias que posibiliten una regulación del sector, y que beneficien a las mujeres inmigrantes. Sacar a la luz el papel y el valor del trabajo de la mujer, como soporte de la pirámide social. Las inmigrantes, además, necesitan tener documentación que les facilite el contrato de trabajo. Y como la sociedad suele caminar por delante de la legislación, quizá es el momento de que estas iniciativas surgidas en la comunidad puedan contemplarse desde la legalidad, antes de que aparezcan verdaderos problemas sociales.

Recibido: 06/07/2009

Aceptado: 09/10/2009

\section{BIBLIOGRAFÍA}

Anderson, B. (2000): Doing the dirty work? The global politics of domestic labour, London, Zed Books.

Bodega, M. I., Cebrián, J. A. y Martín, M. A. (2006): "El crecimiento de la población extranjera en Madrid. Un episodio característico de la inmigración internacional 
en la España del cambio de siglo" Estudios Geográficos LXVII, 261 Julio-Diciembre, 385-416.

Boyd, M. (1984): "At a disadvantage: The occupational attainments of foreign born women in Canada”, International Migration Review, vol. 18, (4), 1091-1119.

Castles, S. y Miller, M. (2004): La era de la migración. Movimientos internacionales de población en el mundo moderno, Miguel Ángel Porrúa, Universidad Autónoma de Zacatecas, México.

Ehrenreich, B. y Hochschchild, R. (eds.) (2002): Global Woman. Nannies, Maids, and Sex Workers in the New Economy, New York, Metropolitan Books.

Everett, S. L. (1969): “A theory of Migration," en J. A. Jackson, (ed.), Migration, Cambridge University Press, pp. 286-287.

Escrivá, A. (2000): “¿Empleadas de por vida? Peruanas en el servicio doméstico de Barcelona” Papers, 60, 327-342.

England, K. y Stiell, B. (1997): "They think you're as stupid as your English is: Constructing foreign domestic workers in Toronto", Environment and Planning A, (29) 195-215.

Gallart, A. (2007): "Sobrecarga del cuidador inmigrante no profesional formal en Barcelona”, Tesis Doctoral. Disponible en: http://www.uic.es/web/imags/tesis12_04_07.pdf

Gamburd, M. R. (2000): The Kitchen Spoon Handle: Transnationalism and Sri Lanka's Migrant Housemaids, Ithaca, NY: Cornell University Press.

George, S. (2005): When Women Come First. Gender and Class in Transnational Migration, Berkeley, University of California Press.

Glick, N. L., Basch, C., Blanc-Szanton (1992): "Transnationalism: A new analytic framework for understanding migration", en Glick, L., C. Basch, (eds.), Towards a transnational perspective on migration: Race, class, ethnicity, and nationalism reconsidered. New York: New York Academy of Sciences, pp. 1-24.

Gregorio, G. (1998): Migración femenina en España. Su impacto en las relaciones de género, Madrid, Nancea.

Izquierdo, A. (2003): "The favorites of the twenty-first century: latin american immigration in Spain", Studi Emigrazione 149.

Kofman, E.M y England, K. (1997): Guest Editorial, Environment and Planning A, 1997; 29: 191-193.

Little, K. (1973): African Women in Towns, London: Cambrigde University Press.

Marcu, S. (2008): "Los desajustes entre la formación y el empleo" en V. Rodríguez (coord.), Inmigración, formación y empleo en la Comunidad de Madrid, Madrid, Ed. Biblioteca Nueva, Consejo Económico y Social, Comunidad de Madrid, pp. 149-170.

Martinez Buján, R. (2006): "El cuidado de ancianos: un nicho laboral para mujeres inmigrantes y un reto de gestión para las entidades del tercer sector", Revista Española del Tercer Sector, (4) 99-127.

Massey, D. R., Alarcón, H., González, y Durand, J. (1987): Return to Aztlán: The Social Process of International Migration from Western Mexico, Berkeley, University of California Press. 
Meil, G. (1999): La postmodernización de la familia española, Madrid, Acento Editorial.

Méndez, R. (2008): "Evolución y características del empleo inmigrante" en V. Rodríguez, (coord.), Inmigración, formación y empleo en la Comunidad de Madrid, Madrid, Biblioteca Nueva, Consejo Económico y Social, Comunidad de Madrid, pp. 105-136.

Moore, H. L. (1991): Antropología y feminismo, Madrid, Cátedra.

Morokvasic, M. (1984): "Birds of Passage are also women", International Migration Review, 18, (4) 886-907.

Mureşan, C. (2005): Introducere in demografie, Cluj-Napoca, Presa Universitară Clujeană.

Oso, L. (1998): La migración hacia España de mujeres jefas de hogar, Madrid: Instituto de la Mujer.

Pajares, M. (2007): Inmigrantes del Este. Procesos migratorios de los rumanos, Ed. Barcelona, Icaria, Colección Antrazyt.

Parella, S. (2003): Mujer, inmigrante y trabajadora: la triple discriminación, Barcelona, Anthropos.

Pedone, C. (2005): "Tú siempre jalas a los tuyos. Cadenas y redes migratorias de las familias ecuatorianas hacia España”, La Migración Ecuatoriana. Transnacionalismo, Redes e Identidades. Ed. Herrera, G. M.C. Carrillo y A. Torres, Quito, Flacso-Plan Migración Comunicación y Desarrollo, pp. 105-43.

Portes, A. y Borock, J. (1989): Contemporary immigration: Theoretical perspectives on its determinants and modes of incorporation, International Migration Review, 23 (3).

Raijman, R. S., Schammah-Gesser, y Kemp, A. (2003): "International Migration, Domestic Work and care work: Undocumented Latina migrants in Israel", Gender and Society, 17 (5): 727-749.

Ravenstein, E. (1885): "The Laws of Migration", Journal of the Statistical Society, 46: $167-235$.

Sandu, D. (2006): "Exploring Europe through work migrations: 1990-2006", Living abroad on a temporary basis. The economic migration of Romanian: 1990-2006. Open Society Fundation Bucarest.

Sassen, S. (1984): "Notes on the Incorporation of Third World Women into Wage-Labor Through Immigration and Off-Shore Production", International Migration Review, 18 (4): 11-44.

Soriano Miras, R. M. (2006): "La inmigración femenina marroquí y su asentamiento en España. Un estudio desde la Grounded Theory", Revista Internacional de Sociología (RIS), vol. LXIV, (43) enero-abril, 169-191.

Suárez Navaz, L. (2005): "Transformaciones de género en el campo transnacional, El caso de las mujeres inmigrantes en España”, en La Ventana. Revista de Estudios de Género, México, 20:20-55.

Torns, T. (1995): "Mercado de trabajo y desigualdad de género", Cuadernos de relaciones laborales, 6: 32-45.

Young, I.M. (1990): Justice and the politics of difference, Princeton, Princeton University Press. 


\title{
RESUMEN
}

El artículo analiza el trabajo que desempeñan las mujeres inmigrantes rumanas, como trabajadoras irregulares en el servicio doméstico de la Comunidad de Madrid, (CAM) haciendo hincapié en el cuidado de personas mayores. Vincula dos tendencias muy presentes en la sociedad española de comienzos del siglo xxI: por un lado, el acentuado envejecimiento de la población y por el otro lado, la inmigración, la mano de obra extranjera necesitada en el sector doméstico y de cuidados de personas mayores. Analiza conjuntamente el contexto de la inmigración de la mujer rumana teniendo en cuenta su situación de partida y trayectoria profesional; se indaga en la situación laboral y en la valoración que realizan las inmigrantes en relación con el trabajo realizado en los domicilios españoles; por último se atiende a las perspectivas de futuro de este sector en el mercado de trabajo español.

PALABRAS ClAVE: sector de trabajo irregular; mujeres extranjeras; envejecimiento.

\begin{abstract}
The article analyzes the work of the women Rumanian immigrants, like irregular workers in the domestic service of the Community of Madrid, (CAM) insisting on the care of elderly. It ties two very present tendencies in the Spanish society of beginnings of the 21st century: on the one hand, the marked aging of the population and on the other side, immigration, foreign manpower needed in the domestic sector and taken care of people majors. It jointly analyzes the context of the immigration of the Rumanian woman considering his departure situation and professional trajectory; it is investigated in the labour situation and the valuation that the immigrants in relation to the work carried out in the Spanish addresses realise; finally it is taken care of the perspective of future of this sector in the market of Spanish work
\end{abstract}

KEY WORDS: sector of irregular work; foreigners women; aging.

\section{RÉSUMÉ}

Larticle analyse le travail que les femmes immigrantes roumaines effectuent, comme travailleuses irrégulières dans le service domestique de la Communauté de Madrid, (CAM) en mettant l'accent sur le soin des vieilles personnes. Il lie deux tendances très présentes dans la société espagnole de commencements du XXIe siècle : d'un côté, le vieillissement accentué de la population et par l'autre côté, l'immigration, la main d'œuvre étrangère eue besoin dans le secteur domestique et des soins de plus grandes personnes. On analyse conjointement le contexte de l'immigration de la femme roumaine en tenant en compte de sa situation de départ et de trajectoire professionnelle; il est recherché dans la situation de travail et dans l'évaluation que les immigrantes réalisent en relation avec le travail réalisé dans les domiciles espagnols; on fait attention finalement aux perspectives d'avenir de ce secteur sur le marché de travail espagnol.

MoTS CLÉS: secteur de travail irrégulier; femmes étrangères; vieillissement. 
Anexo

ENTREVISTAS EN PROFUNDIDAD: INMIGRANTES RUMANAS FICHAS TÉCNICAS

\begin{tabular}{|c|c|c|c|c|c|c|c|c|}
\hline $\mathrm{N}^{\mathrm{o}}$ & $\begin{array}{l}\text { Fecha } \\
\text { entrevista }\end{array}$ & $\begin{array}{l}\text { Tiempo } \\
\text { en España }\end{array}$ & Edad & $\begin{array}{l}\text { Estado } \\
\text { civil }\end{array}$ & $\begin{array}{l}\text { Profesión } \\
\text { en su país }\end{array}$ & $\begin{array}{l}\text { Tamaño } \\
\text { hogar }\end{array}$ & Régimen & Reclutamiento \\
\hline 1 & 12.01 .2008 & 1,4 años & 41 & casada & $\begin{array}{l}\text { Trabajadora industria } \\
\text { textil }\end{array}$ & 4 & Externa & Coslada \\
\hline 2 & 13.01 .2008 & 5 años & 50 & divorciada & $\begin{array}{l}\text { Trabajadora fábrica de } \\
\text { chocolate. Masajista }\end{array}$ & $\begin{array}{l}\text { Vive con } \\
\text { sus } 2 \text { hijos }\end{array}$ & Externa & Madrid \\
\hline 3 & 15.01 .2008 & 5 meses & 51 & divorciada & Comercio & 1 & Interna & Madrid \\
\hline 4 & 16.012008 & 8 meses & 37 & casada & Vigilante & 3 & Interna & Madrid \\
\hline 5 & 16.01 .2008 & 4 años & 26 & soltera & Hostelería & 1 & Interna & Madrid \\
\hline 6 & 17.01 .2008 & 6 años & 41 & soltera & $\begin{array}{l}\text { Mecánica/ } \\
\text { Construcciones }\end{array}$ & 1 & Interna & Alcobendas \\
\hline 7 & 19.01 .2008 & 3 años & 48 & soltera & Mecánica & 1 & Interna & Madrid \\
\hline 8 & 19.01 .2008 & 4 años & 37 & soltera & Industria porcelana & 1 & Interna & Madrid \\
\hline 9 & 22.01 .2008 & 3 años & 43 & casada & $\begin{array}{l}\text { Varios empleos: } \\
\text { Comercio, industria }\end{array}$ & 2 & Externa & Torrejón de Ardóz \\
\hline 10 & 26.01 .2008 & 1,8 años & 40 & divorciada & $\begin{array}{l}\text { Administrativa, } \\
\text { fábrica de madera, } \\
\text { hostelería. } \\
\text { Licenciatura en } \\
\text { Informática } \\
\text { (posteriormente) }\end{array}$ & 1 hijo & Externa & Móstoles \\
\hline 11 & 27.01 .2008 & 4,2 años & 51 & casada & Contable & 4 & Externa & Alcobendas \\
\hline 12 & 27.01 .2008 & 3 años & 61 & viuda & $\begin{array}{l}\text { Trabajadora } \\
\text { confecciones. } \\
\text { Jubilada }\end{array}$ & 3 & Interna & Móstoles \\
\hline 13 & 3.02 .2008 & 2 años & 46 & casada & $\begin{array}{l}\text { Trabajadora } \\
\text { electrotécnica. } \\
\text { Licenciada en } \\
\text { Empresariales }\end{array}$ & 4 & Por horas & Arganda del Rey \\
\hline 14 & 3.02 .2008 & $\begin{array}{c}2 \text { años } \\
\text { movilidad } \\
\text { circulatoria }\end{array}$ & 44 & casada & $\begin{array}{l}\text { Bachillerato. } \\
\text { Trabajadora mina. } \\
\text { Control técnico de } \\
\text { calidad }\end{array}$ & 4 & Interna - & Coslada \\
\hline 15 & 3.02 .2008 & 3 años & 29 & divorciada & $\begin{array}{l}\text { Formación profesional } \\
\text { Peluquera }\end{array}$ & 1 hijo & Por horas & Alcobendas \\
\hline 16 & 3.02 .2008 & 2 años & 38 & casada & Trabajadora carburantes & 4 & Externa & Arganda del Rey \\
\hline 17 & 5.02 .2008 & 4 años & 53 & viuda & Trabajadora transportes & 3 & Por horas & Coslada \\
\hline 18 & 5.02 .08 & 4,3 años & 50 & viuda & Modista & 3 & Por horas & Torrejón de Ardóz \\
\hline 19 & 5.02 .08 & 1,5 años & 51 & viuda & Estudios básicos & 3 & Interna & Torrejón de Ardoz \\
\hline 20 & 9.02 .08 & 4 años & 40 & casada & Bachillerato & 4 & Interna & Coslada \\
\hline
\end{tabular}

